\title{
The Impact of Attractiveness on Athletic Performance of Tennis Players
}

\author{
Linn-Brit Bakkenbüll ${ }^{1}$ \\ ${ }^{1}$ Institute for Organisational Economics, University of Münster, Münster, Germany \\ Correspondence: Linn-Brit Bakkenbüll, Institute for Organisational Economics, University of Münster, Scharnhorststraße \\ 100, 48151 Münster, Germany.
}

Received: January 17, 2017

Accepted: February 9, $2017 \quad$ Available online: February 10, 2017

doi:10.11114/ijsss.v5i3.2217

URL: http://dx.doi.org/10.11114/ijsss.v5i3.2217

\begin{abstract}
The present study examines whether there is an impact of physical attractiveness on athletic performance of professional tennis players. Moreover, this study analyses whether there are gender-specific differences. Different multiple regressions reveal a significantly positive relationship between physical attractiveness and athletic performance. Regression results show that there are no differences between male and female tennis players. Furthermore, this study examines determinants that influence athletic performance. For managers or coaches, the findings suggest that managers or coaches would benefit from hiring more attractive tennis players. More attractive and therefore more successful tennis players may earn higher prize money and generate greater contracts, for example, in terms of sponsoring. This also creates greater revenues for managers or coaches. This holds true for both, male and female tennis players.
\end{abstract}

Keywords: physical attractiveness, sporting success, prize money, gender, tennis

\section{Introduction}

Professional athletes, and those aspiring to become professionals, distinguish themselves through hard work, ambitiousness and discipline. However, new research points to another trait of the professional athletes, that is, attractiveness. In the general field of attractiveness research, several studies show that more attractive people have different advantages in comparison to less attractive ones. For example, more attractive people are liked more (Byrne, London, \& Reeves, 1968), receive more support (Benson, Karabenic, \& Lerner, 1976), are attributed more socially desirable characteristics (Dion, Berscheid, \& Walster, 1972), receive more favourable task performance ratings (Landy \& Sigall, 1974) and have a higher degree of happiness and self-confidence (Mathes \& Kahn, 1975; Shackelford \& Larsen, 1999; Woodman \& Hardy, 2003). Additionally, studies show that more attractive people have higher athletic performances, (Bakkenbüll \& Kiefer, 2015; Postma, 2014; Williams, Park, \& Wieling, 2010) resulting in a higher market value (Rosar, Hagenah, \& Klein, 2014).

The relationship between athletic performance and physical attractiveness might be explained by the evolutionary theory and specifically by the selection theory of Charles Darwin. It says that traits which increase the probability of survival and which ensure the reproduction will prevail over time (natural selection). The sexual selection theory as a special case of the natural selection theory implies that characteristics that have no influence on survival or that may even threaten it, may also be reproduced in the population. This is the case when such traits increase reproductive success. With regard to physical attractiveness, studies point out that physical fitness and thus physical health result in more attractive faces signalled by more symmetric and health-looking faces (Hönekopp, Bartholomé, \& Jansen, 2004; Hönekopp, Rudolph, Beier, Liebert, \& Müller, 2007; Shackelford \& Larsen, 1999). More symmetric faces reflect the ability to manage the challenges and changes of the environment (Fink \& Penton-Voak, 2002). These "good genes" are more likely to transmit to their descendants. This results in higher reproductive success and evolutionary benefits followed by an increase of surviving chances of these genes. Consequently, the evolutionary theory suggests that physical fitness and thus athletic performance influence attractiveness. At this point, the question arises whether the causality might be vice versa. The results of attractiveness studies (e.g. Bakkenbüll \& Kiefer, 2015; Postma, 2014; Rosar et al., 2014; Williams et al., 2010) raise the question whether there is a relationship between physical attractiveness and athletic performance. Therefore, this study examines the first hypothesis: Physical attractiveness influences athletic performance in a positive way. While many studies examined the effect of physical attractiveness and athletic performance for each gender separately, no study examined gender-specific differences in this context yet. 
Concerning the effect of attractiveness on athletic performance, there might be differences between men and women. First, it is conceivable that the correlation between self-confidence, self-esteem, or outer appearance in general, and attractiveness is stronger for women than for men. This may result in a stronger relationship between attractiveness and performance. Second, there might be gender-specific differences regarding the appreciation and importance of outer appearance. While men are less interested in it, women typically strive to receive positive attention and encouragement by their outer appearance. Third, attractiveness is an indicator of many traits leading to greater success. In the childhood, the attractiveness of girls might be recognised earlier than in the case of boys because the latter develop the attributes of attractive men over time. Thus, support by family or coaches in the childhood is stronger for girls than for boys resulting in gender-specific differences in later years. These thoughts outline the presence of gender-specific differences. Therefore, this study examines the second hypothesis: There are gender-specific differences with respect to the impact of physical attractiveness on athletic performance. To the best of my knowledge, there are no previous studies which investigate this, in particular, for professional tennis players.

\section{Literature Review and Theoretical Framework}

This section gives a short literature review about already existing studies dealing with the relationship between physical attractiveness and athletic performance. There are some studies examining the link between physical attractiveness and athletic performance. Up to now, no study analyses this relationship in consideration of gender. Furthermore, this section includes a short overview of different theories that can be used to explain the relationship between physical attractiveness and athletic performance in general.

Postma (2014) examines the direct effect of physical attractiveness on athletic performance by using data from elite professional male cyclists. He depicts a significantly positive relationship between attractiveness of a cyclist and his performance at the Tour de France in 2012. Williams et al. (2010) gain similar results for National Football League quarterbacks. Their research shows that more athletic quarterbacks have more attractive faces. Rosar et al. (2014) analyse how facial attractiveness of professional male football players in the German Bundesliga influence their market value. They show that facial attractiveness has a positive effect on a player's market value. Bakkenbüll and Kiefer (2015) analyse the influence of physical attractiveness on athletic performance for professional female tennis players and find a significantly positive impact. Yet, there is no study that analyses the impact of physical attractiveness on athletic performance depending on gender for the same type of sport.

At first glance, it is not clear how athletic performance can be influenced by physical attractiveness. Corresponding to Köhler (1984), attractiveness is an objective or intersubjective characteristic of the person considered. Furthermore, Hamermesh and Biddle (1994) show that resulting variations in the valuation of physical attractiveness go back to differences in taste and cultures. This effect is referred to the Attractiveness Consensus (Cunningham, 1986; Rosar, Hagenah, \& Klein, 2010) and serves as a basis for the following theoretical effects of physical attractiveness. First, the Attractiveness Attention Boost (Rosar et al., 2010) indicates that more attractive persons receive higher attention from their social environment. Furthermore, they benefit from the fact that their actions and statements keep longer in mind (Maner et al., 2003). The Attractiveness Stereotype as a second explanatory mechanism focuses on the hypothetical fact that more attractive people would be more high-performing, hard-working, intelligent and creative (Dermer \& Thiel, 1975; Eagly, Ashmore, Makhijani, \& Longo, 1991; Feingold, 1992). Third, the Attractiveness Treatment Advantage (Rosar et al., 2010) implies that more attractive people get a higher range of support from their social environment and interaction partners because of higher respect and appreciation (Benson et al., 1976; Dion et al., 1972). The aforementioned mechanisms can be combined to the so-called Attractiveness Competition Advantage (Rosar et al., 2010). This mechanism attests more attractive persons an advantage over less attractive ones. All of these mechanisms predict that more attractive people get higher advancement and support resulting in higher performance. In the context of professional tennis players, it is imaginable that more attractive tennis players receive more support by their families, coaches, and managers, particularly at the beginning of a possible professional career. This preferential treatment leads in later years to a higher athletic performance and consequently to greater athletic success.

The so-called Pygmalion Effect (Rejeski, Darracott, \& Hutslar, 1979) serves as a second theoretical explanatory approach. It is assumed that the performance of people increases with the expectation placed upon people. As a result, higher expectations lead to higher competition levels, better quality coaching, and more support from sponsors. With regard to the research subject, the Pygmalion Effect leads to a selection bias in favour of more attractive people because coaches or sponsors might have greater expectations about their ability. This is because of the Attractiveness Stereotype assuming higher skills of more attractive people that leads to higher support levels by coaches and consequently translates into better performance.

\section{Dataset and Descriptive Statistics}

The dataset contains the single ranking at the $40^{\text {th }}$ calendar week in 2014 of the top 100 professional male and female 
tennis players. The Association of Tennis Professionals (ATP) serves as the source for the male single ranking, for women it is the Women's Tennis Association (WTA). The needed personal as well as career-related data were collected from the official website of the ATP and WTA. The physical attractiveness of each tennis player was determined using an online-questionnaire in conformity with the Truth of Consensus Method (Patzer, 1985). For this purpose, portraits of the top 100 male and female tennis players, taken from the ATP or WTA website or from the German sport magazine Kicker, were selected such that face and neck of each tennis player were photographed in a frontal position. To minimise distortion of the evaluation background and clothes were standardised and jewellery or hats were deleted. To control for further potential distortion generated by the position of a picture, the questionnaires differed concerning the image position. Each picture was presented at different positions.

The online-questionnaire starts with some information about the purpose of the survey. To reduce the influence of recognition and popularity that could distort the pure evaluation of attractiveness, participants were not informed that they evaluated tennis players. The physical attractiveness was measured with an eight point Likert scale, ranging from zero for very unattractive to seven for very attractive. After evaluation, participants were asked whether they could identify any of the persons. If participants confirm this question, there evaluation was excluded.

The online-questionnaire was propagated using various social media as well as internal platforms for students of various Universities. In sum, 684 persons participated in the survey. Thirty-two participants recognised any of the persons shown. Consequently, there were 652 participants whose evaluations have been used. Every picture of the tennis players was evaluated between 31 and 54 times. According to Rosar et al. (2010), 24 evaluations are sufficient to reach a robust attractiveness rating score. In order to calculate the value for physical attractiveness, all evaluations of each tennis player were summed up and divided by the numbers of evaluators.

As an indicator of the athletic performance of each tennis player, the prize money earned for the 2012 and 2013 single seasons as well as for the whole career at the end of 2012 and 2013 is used. Descriptive statistics of male tennis players in Table 1 show that on average, male tennis players earned about 0.82 million US\$ in 2012 and 1.02 million US\$ in 2013. Descriptive statistics of female tennis players in Table 2 show that on average, they earned about 0.57 million US\$ in 2012 and 0.72 million US\$ in 2013. Regarding the prize money earned in the whole career at the end of 2012 and 2013, the mean values are 4.69 million US\$ and 5.71 million US\$ for male tennis players and 2.88 million US\$ and 3.60 million US\$ for female tennis players. For the empirical analysis, the different prize money variables were logarithmised.

Besides the prize money earned, the number of single tournaments played in 2012 and 2013 as well as the number of single tournaments played in the whole career at the end of 2012 and 2013 were determined. The athletic performance measured by several prize money variables has to be seen in the context of the number of tournaments played in the year considered. On average, the female tennis players played 21.59 tournaments in 2012 and 21.43 tournaments in 2013. Male tennis players participated in 23.39 tournaments in 2012 and 24.69 tournaments in 2013 on average. Concerning the number of tournaments in the whole career at the end of 2012 and 2013, the mean values for female tennis players are 148.32 and 169.75 and for male tennis players 196.94 and 221.63.

A further control variable is the body mass index (BMI). The mean of the BMI for male tennis player is 22.85 , for female tennis player it is 21.41. A value between 18.5 and 24.9 implies normal weight for adults (World Health Organization, 2015).

Another explanatory variable is the number of years as a professional tennis player in 2012 and 2013. The variables measure the duration of the professional career at the time. Descriptive statistics show that on average the career duration of the analysed tennis players is 7.99 in 2012 and 8.99 in 2013 for male tennis players and 6.9 in 2012 and 7.9 in 2013 for female tennis players. The longest professional career has been lasting for 17 years in 2013 for male tennis players and 19 years for female tennis players. 
Table 1. Variable definitions and descriptive statistics for male tennis players

\begin{tabular}{|c|c|c|c|c|c|c|}
\hline Variables & Description & Obs. & Mean & SD & Min & Max \\
\hline PM_2012 & Prize money earned in 2012 (in million US\$) & 100 & 0.82 & 1.73 & 0 & 12.80 \\
\hline PM_2013 & Prize money earned in 2013 (in million US\$) & 100 & 1.02 & 2.03 & 0.03 & 14.56 \\
\hline PMCa_2012 & $\begin{array}{l}\text { Prize money earned in the career at the end } \\
\text { of } 2012 \text { (in million US\$) }\end{array}$ & 100 & 4.69 & 10.33 & 0.01 & 75.31 \\
\hline PMCa_2013 & $\begin{array}{l}\text { Prize money earned in the career at the end } \\
\text { of } 2013 \text { (in million US\$) }\end{array}$ & 100 & 5.71 & 11.93 & 0.05 & 78.50 \\
\hline Attractiveness & Physical attractiveness of tennis players & 100 & 3.02 & 0.73 & 0.90 & 4.82 \\
\hline BMI & $\begin{array}{l}\text { Body-Mass-Index (BMI) defined by BMI = } \\
\mathrm{m} / \mathrm{I}^{2}\end{array}$ & 100 & 22.85 & 1.60 & 19.60 & 26.88 \\
\hline Pro_Years_2012 & $\begin{array}{l}\text { Number of years as professional tennis } \\
\text { player in } 2012\end{array}$ & 100 & 7.99 & 3.45 & 0 & 16 \\
\hline Pro_Years_2013 & $\begin{array}{l}\text { Number of years as professional tennis } \\
\text { player in } 2013\end{array}$ & 100 & 8.99 & 3.45 & 0 & 17 \\
\hline Tours_2012 & Tournaments played in 2012 & 100 & 23.39 & 6.04 & 0 & 33 \\
\hline Tours_2013 & Tournaments played in 2013 & 100 & 24.69 & 5.32 & 8 & 35 \\
\hline ToursC_2012 & $\begin{array}{l}\text { Tournaments played in the career at the end } \\
\text { of } 2012\end{array}$ & 100 & 196.94 & 76.05 & 8 & 344 \\
\hline ToursC_2013 & $\begin{array}{l}\text { Tournaments played in the career at the end } \\
\text { of } 2013\end{array}$ & 100 & 221.63 & 76.62 & 20 & 373 \\
\hline
\end{tabular}

Table 2. Variable definitions and descriptive statistics for female tennis players

\begin{tabular}{|c|c|c|c|c|c|c|}
\hline Variables & Description & Obs. & Mean & SD & Min & Max \\
\hline PM_2012 & Prize money earned in 2012 (in million US\$) & 100 & 0.57 & 1.24 & 0.07 & 7.31 \\
\hline PM_2013 & Prize money earned in 2013 (in million US\$) & 100 & 0.72 & 1.43 & 0.01 & 11.99 \\
\hline PMCa_2012 & $\begin{array}{l}\text { Prize money earned in the career at the end } \\
\text { of } 2012 \text { (in million US\$) }\end{array}$ & 100 & 2.88 & 5.65 & 0.08 & 38.98 \\
\hline PMCa_2013 & $\begin{array}{l}\text { Prize money earned in the career at the end } \\
\text { of } 2013 \text { (in million US\$) }\end{array}$ & 100 & 3.60 & 6.86 & 0.04 & 50.97 \\
\hline Attractiveness & Physical attractiveness of tennis players & 100 & 3.55 & 1.07 & 1.05 & 5.54 \\
\hline BMI & $\begin{array}{l}\text { Body-Mass-Index (BMI) defined by BMI = } \\
\mathrm{m} / \mathrm{l}^{2}\end{array}$ & 99 & 21.14 & 1.31 & 16.69 & 24.24 \\
\hline Pro_Years_2012 & $\begin{array}{l}\text { Number of years as professional tennis } \\
\text { player in } 2012\end{array}$ & 100 & 6.9 & 4.12 & 0 & 18 \\
\hline Pro_Years_2013 & $\begin{array}{l}\text { Number of years as professional tennis } \\
\text { player in } 2013\end{array}$ & 100 & 7.9 & 4.12 & 0 & 19 \\
\hline Tours_2012 & Tournaments played in 2012 & 100 & 21.59 & 5.12 & 8 & 30 \\
\hline Tours_2013 & Tournaments played in 2013 & 100 & 21.43 & 5.56 & 7 & 32 \\
\hline ToursC_2012 & $\begin{array}{l}\text { Tournaments played in the career at the end } \\
\text { of } 2012\end{array}$ & 100 & 148.32 & 74.96 & 13 & 330 \\
\hline ToursC_2013 & $\begin{array}{l}\text { Tournaments played in the career at the end } \\
\text { of } 2013\end{array}$ & 100 & 169.75 & 74.81 & 30 & 357 \\
\hline
\end{tabular}

Note. Due to missing information about the weight of one female tennis player, she was excluded from the analysis.

\section{Empirical Results}

To test the two hypotheses multiple regressions were run to analyse the effect of physical attractiveness on athletic performance. Two out of four models regress the logarithmised prize money earned in single seasons in 2012 and 2013 to physical attractiveness, the BMI, the number of years as professional tennis player in the considered year as well as single tournaments played in the considered season. The other two models regress the logarithmised prize money earned in the whole career at the end of 2012 and 2013 to slightly adjusted explanatory variables. This means that the number of single tournaments played comprises the number of single tournaments played at the end of the whole career in 2012 and 2013. The number of years as professional tennis player in the considered year, the BMI and the score for physical attractiveness are the same. To control for gender-specific differences, interaction terms are used. 
Table 3. Results of multiple regressions for professional male and female tennis players

\begin{tabular}{|c|c|c|c|c|}
\hline \multirow{2}{*}{$\begin{array}{l}\text { Explanatory } \\
\text { variables }\end{array}$} & \multicolumn{4}{|c|}{ Dependent variables } \\
\hline & LN_PM_2012 & LN_PM_2013 & LN_PM_Ca 2012 & LN_PM_Ca 2013 \\
\hline \multirow[t]{2}{*}{ Attractiveness } & $.269^{+(.061)}$ & $.183^{+(.081)}$ & $.232 *(.037)$ & $.224 *(.026)$ \\
\hline & $(.142)$ & $(.104)$ & $(.111)$ & $(.099)$ \\
\hline \multirow[t]{2}{*}{ Gender } & $.111^{(.656)}$ & $.443 *(.020)$ & $.097^{(.638)}$ & $.241^{(.198)}$ \\
\hline & $(.249)$ & $(.188)$ & $(.205)$ & $(.186)$ \\
\hline \multirow{2}{*}{ Attractiveness*Gender } & $-.254^{(.303)}$ & $-.082^{(.651)}$ & $-.197^{(.307)}$ & $-.151^{(.384)}$ \\
\hline & $(.246)$ & $(.181)$ & $(.192)$ & $(.173)$ \\
\hline \multirow[t]{2}{*}{ BMI } & $-.057^{(.615)}$ & $-.120^{(.150)}$ & $-.032^{(.719)}$ & $-.058^{(.468)}$ \\
\hline & $(.113)$ & $(.083)$ & $(.088)$ & $(.080)$ \\
\hline \multirow[t]{2}{*}{ BMI*Gender } & $.076^{(.604)}$ & $.142^{(.189)}$ & $.113^{(.322)}$ & $.109^{(.289)}$ \\
\hline & $(.147)$ & $(.107)$ & $(.114)$ & $(.103)$ \\
\hline \multirow[t]{2}{*}{ Pro_Years } & $.207 * * *(.000)$ & $.129 * * *(.000)$ & $.247 * * *(.000)$ & $.232 * * *(.000)$ \\
\hline & $(.036)$ & $(.027)$ & $(.051)$ & $(.044)$ \\
\hline \multirow[t]{2}{*}{ Pro_Years*Gender } & $-.030^{(.596)}$ & $-.019^{(.644)}$ & $.012^{(.891)}$ & $.036^{(.643)}$ \\
\hline & $(.056)$ & $(.042)$ & $(.091)$ & $(.078)$ \\
\hline \multirow[t]{2}{*}{ Tours } & $.005^{(.860)}$ & $-.009^{(.659)}$ & $.006 *(.019)$ & $.002^{(.374)}$ \\
\hline & $(.030)$ & $(.020)$ & $(.003)$ & $(.002)$ \\
\hline \multirow[t]{2}{*}{ Tours*Gender } & $.075^{+(.054)}$ & $-.021^{(.466)}$ & $-.003^{(.563)}$ & $-.003^{(.502)}$ \\
\hline & $(.039)$ & $(.028)$ & $(.004)$ & $(.004)$ \\
\hline \multirow{2}{*}{ Constant } & $12.265 * * *(.000)$ & $12.647 * * *(.000)$ & $13.783 * * *(.000)$ & $14.175 * * *(.000)$ \\
\hline & $(.177)$ & $(.133)$ & $(.144)$ & $(.131)$ \\
\hline Significance & .000 & .000 & .000 & .000 \\
\hline Obs. & 200 & 200 & 200 & 200 \\
\hline Adjusted $\mathrm{R}^{2}$ & .222 & .169 & .573 & .486 \\
\hline
\end{tabular}

Note: Dependent variables: LN_PM_2012/2013: logarithmised prize money earned for the year 2012 and 2013;

LN_PMCa_2012/2013: logarithmised prize money earned for the whole career at the end of 2012 and 2013. ${ }^{+} \mathrm{p}<.10 ; *^{*} \mathrm{p}<.05$;

$* * \mathrm{p}<.01 ; * * * \mathrm{p}<.001$. Displayed are the unstandardized coefficients, standard errors are in parentheses.

Table 3 shows that the impact of physical attractiveness on athletic performance is significantly positive in all models. In figures, the coefficients of physical attractiveness show that an increase of one point is associated with increases of 26.9 and 18.3 percentage points in prize money earned for single season in 2012 and 2013 and with increases of 23.2 and 22.4 percentage points in prize money earned for the whole career at the end of 2012 and 2013. Therefore, the first hypothesis can be confirmed.

Regarding the gender dummy variable (one=male, zero=female), the results show that gender has a significantly positive impact on athletic performance for the 2013 single season only. The coefficient of gender means that an increase of one point is associated with increases of 44.3 percentage points in prize money earned for the 2013 single season. In general, professional male tennis players earned about 44.3 per cent more than female tennis players in 2013. This difference is significant. In all other models, gender has no significant impact on prize money earned. This means that there are no significant differences between the prize money earned of male and female tennis players.

The interaction term of attractiveness and gender is in all models significantly negative. The negative sign means that changing the gender variable from zero (women) to one (men) weakens the impact of attractiveness on athletic performance. This suggests that the impact of attractiveness on athletic performance is weaker for professional male tennis players than for professional female tennis players. However, this effect is nonsignificant. This means that there are no significant differences between genders. Therefore, the second hypothesis cannot be confirmed.

Furthermore, the multiple regressions indicate that there are other determinants that influence the performance variables in a more or less significant way. The BMI and the interaction term are nonsignificant. Therefore, the relationship between body height and body weight of professional tennis players has in general no significant impact on the athletic performance. Furthermore, there are also no significant differences regarding the impact of BMI on athletic performance between professional male and female tennis players. Thus, athletic performance of professional tennis players is to some extent independent of the body type. However, this does not mean that physical fitness or constitution have no impact on athletic performance. Rather, this means that the range of differences is at any rate very small for professional athletes because there is a certain level of fitness needed to achieve good performance and thus to be successful. Regarding the impact of the number of tournaments played in the considered season, regression results show that in three of four models the impact is nonsignificant. Only the number of single tournaments played for the whole career at the end of 2013 influences the prize money earned in a significantly positive way. Thus, an increase of one tournament implies a 0.6 percentage point increase in prize money earned for the whole career at the end of 2013. Regarding the interaction terms, note that the terms are in three of four models nonsignificant, too. Only the impact of the interaction term for the prize money earned in 2012 is significantly positive. This suggests that the impact of the 
number of single tournaments played in 2012 on athletic performance is greater for professional male tennis players than for professional female tennis players. Last, the duration of the career has in all models a significantly positive impact, meaning that prize money earned increases with the number of years as professional tennis player. More precisely, an increase of one year as professional tennis player is associated with increases of 20.7 percentage points and 12.9 percentage points in prize money earned for single seasons in 2012 and 2013 and increases of 24.7 and 23.2 percentage points in prize money earned over the whole career at the end of 2012 and 2013 . The increasing effect for the whole career is quite intuitive because longer careers simply imply more time for winning prize money. Moreover, tennis players with longer careers have more experience and thus perform better and more proficiently (Del Corral, 2009). The interaction terms have no significant impact on athletic performance. This means that there are no gender-specific differences regarding the impact of the duration of the career as professional tennis player and the prize money earned.

\section{Discussion and Conclusion}

The purpose of this paper is to test the hypothetical relationship between physical attractiveness and athletic performance and, in particular, the existence of possible gender-specific differences. In general, the findings confirm an impact of physical attractiveness of professional tennis players on prize money earned. This result is in accordance with results of previous studies that show a significantly positive impact for different types of sport, too (e.g. Bakkenbüll \& Kiefer, 2015; Postma, 2014; Rosar et al., 2014; Williams et al., 2010). However, the findings cannot identify the exact reason for the effect of physical attractiveness.

The aforementioned research literature analyses the relationship between attractiveness and athletic performance for only one gender. Thus, the underlying paper analyses this impact with special attention to gender in order to identify gender-specific differences in a unique dataset. With the given dataset, it is not possible to point out gender-specific differences, in particular concerning the impact of physical attractiveness on athletic performance for professional male and female tennis players. Regarding the labour market, Hamermesh and Biddle (1994) found similar results. As one result, unattractive people earn less than average-looking people, who earn less than good-looking people do. These effects are for men at least as strong as for women. Regarding the influence of school grades, Dunkake, Kiechle, Klein, and Rosar (2012) show that, on one hand, school grades are significantly influenced by physical attractiveness. On the other hand, there are nonsignificant differences between boys and girls.

The fact that there are no differences between physical attractiveness and athletic performance can be explained by the impact of the aforementioned Pygmalion Effect and the Attractiveness Stereotype. According to these two effects, the performance of people increases with the expectation placed upon people that leads to higher competition levels, better quality coaching and more support from sponsors. This leads to a selection bias in favour of more attractive people because coaches or sponsors may be optimistic about their ability. Rosenthal and Jacobson (1968) show that the "social influence process" is likely to exist both genders. Consequently, the Pygmalion Effect and the support by the family or coaches affect both genders. Thus, there are no gender-specific differences caused by different support levels in the early childhood.

A further possible explanation can be derived from the relationship between physical attractiveness and physical fitness. This relation was proven for male and female athletes (Hönekopp et al., 2004; Hönekopp et al., 2007). These studies show that facial attractiveness signals physical fitness for women while the physical fitness for men is signalled by body attractiveness that in turn can be interpreted as facial attractiveness (Shoup \& Gallup, 2008). Nevertheless, the relationship between physical attractiveness and physical fitness can be interpreted differently. Athletes with better physical fitness might have a healthier lifestyle that in turn results in more healthy-looking and thus more attractive faces. However, to trace this discussion, it would be helpful to test the relationship between facial attractiveness and physical fitness for non-active people.

Another possible explanation can be derived from a study of Mutz and Meier (2016). They show that public interest in athletes positively depends on athletic performance and physical attractiveness. Moreover, this impact is verifiably for male and female athletes. In other words, athletes who perform better receive higher public attention and can be seen as a type of superstar. These superstars are more attractive to receive advertising and sponsoring contracts. If these athletes are also more physically attractive, they have the best chances to get lucrative sponsoring and advertising contracts (Yu, 2005) leading to additional income that provides a further incentive for attractive athletes to perform better. This chain of action should hold for women as well as for men. This assumption is supported by Hakim (2010) who points out that in the $21^{\text {st }}$ century, men in Western Europe spend more time and money into their outer appearance to increase their erotic capital to get the aforementioned lucrative sponsoring and advertising contracts in sport. While female athletes pay attention to their outer appearance for a long time, for men, this development is new.

The correlation between facial attractiveness and self-esteem serves as a last explanation why there are no 
gender-specific differences concerning the relationship between facial attractiveness and athletic performance. In general, Taylor (1987) shows that self-confidence is a significant impact factor on performance. Mahoney and Avener (1977) depict a positive relationship between self-confidence and athletic performance for male gymnasts. Gould, Weiss, and Weinberg (1981) show similar results for wrestling. Ichraf, Ali, Khaled, Liwa, and Ali (2013) find that self-confidence and performance are linked in a positive way in individual sports for both male and female athletes. Thornton and Ryckman (1991) show a positive relationship between attractiveness and self-esteem or self-confidence for both genders. Therefore, attractiveness produces higher self-confidence that in turn results in higher athletic performance for male and female athletes equally.

The present study depicts a significantly positive effect of physical attractiveness on athletic performance for professional male and female athletes. However, the results do not confirm a gender-specific difference for this relationship. For managers or coaches, the findings suggest that managers or coaches would benefit from hiring more attractive tennis players. More attractive and therefore more successful tennis players may earn higher prize money and generate greater contracts, for example, in terms of sponsoring. This also creates greater revenues for managers or coaches. This holds true for both, male and female tennis players.

Nevertheless, the study has some limitations. First, the dataset with the top 100 male and female tennis players is very small. In addition, the evaluated athletes are those with the highest standard of performance so that differences are marginal. To receive higher diversification, it would make sense to analyse the research idea with no professional athletes or extend the dataset to amateur players. Moreover, further research may consider other kinds of individual sports to confirm the results of this study. In addition, the findings provide no evidence for the direction of the effect which may also be the other way around.

\section{Acknowledgements}

The author would like to thank Prof. Dr. Alexander Dilger for valuable suggestions and comments that noticeably improved this paper. In addition, the author would like to thank especially Dr. Marco Bade as well as Dr. Stephanie Kiefer and Katharina Spindler. The author is alone responsible for any remaining errors.

\section{References}

Bakkenbüll, L. B., \& Kiefer, S. (2015). Are attractive female tennis players more successful? An empirical analysis. Kyklos - International Review of Social Sciences, 68(4), 443-458. https://doi.org/10.1111/kykl.12090

Benson, P. L., Karabenic, S. A., \& Lerner, R. M. (1976). Pretty pleases: The effects of physical attractiveness on race, sex and receiving help. Journal of Experimental Social Psychology, 12(5), 409-415. https://doi.org/10.1016/0022-1031(76)90073-1

Byrne, D., London, O., \& Reeves, K. (1968). The effect of physical attractiveness, sex, and attitude similarity on interpersonal attraction. Journal of Personality, 36(2), 259-271. https://doi.org/10.1111/j.1467-6494.1968.tb01473.x

Cunningham, M. R. (1986). Measuring the physical in physical attractiveness: Quasi-experiments on the sociobiology of female facial beauty. Journal of Personality and Social Psychology, 50(5), 925-935. https://doi.org/10.1037/0022-3514.50.5.925

Del Corral, J. (2009). Competitive balance and match uncertainty in Grand-Slam tennis: Effects of seeding system, gender, and court surface. Journal of Sports Economics, 10(6), 563-581. https://doi.org/10.1177/1527002509334650

Dermer, M., \& Thiel, D. L. (1975). When beauty may fail. Journal of Personality and Social Psychology, 31(6), 1168-1176. https://doi.org/10.1037/h0077085

Dion, K. K., Berscheid, E., \& Walster, E. (1972). What is beautiful is good. Journal of Personality and Society Psychology, 24(3), 285-290. https://doi.org/10.1037/h0033731

Dunkake, I, Kiechle, T., Klein, M., \& Rosar, U. (2012). Good looks, good grades? An empirical analysis of the influence of student's physical attractiveness on grading by teachers. Zeitschrift für Soziologie, 41(2), 142-161.

Eagly, A. H., Ashmore, R. D., Makhijani, M. G., \& Longo, L. C. (1991). What is beautiful is good, but...: A meta-analytic review of research on the physical attractiveness stereotype. Psychological Bulletin, 110(1), 109-128. https://doi.org/10.1037/0033-2909.110.1.109

Feingold, A. (1992). Good-looking people are not what we think. Psychological Bulletin, 111(2), 304-341. https://doi.org/10.1037/0033-2909.111.2.304

Fink, B., \& Penton-Voak, I. (2002). Evolutionary Psychology of facial attractiveness. Current Directions in Psychological Science, 11(5), 154-158. https://doi.org/10.1111/1467-8721.00190 
Gould, D., Weiss, R., \& Weinberg, R. (1981). Psychological characteristics of successful and unsuccessful big ten wrestlers. Journal of Sport Psychology, 3(1), 69-81. https://doi.org/10.1123/jsp.3.1.69

Hakim, C. (2010). Erotic Capital. European Sociological Review, 26(5), 499-518. https://doi.org/10.1093/esr/jcq014

Hamermesh, D. S., \& Biddle, J. E. (1994). Beauty and the labour market. American Economic Review, 84(5), 1174-1194.

Hönekopp, J., Bartholomé, T., \& Jansen, G. (2004). Facial attractiveness, symmetry, and physical fitness in young women. Human Nature, 15(2), 147-167. https://doi.org/10.1007/s12110-004-1018-4

Hönekopp, J., Rudolph, U., Beier, L., Liebert, A., \& Müller, C. (2007). Physical attractiveness of face and body as indicators of physical fitness in men. Evolution and Human Behavior, 28(2), 106-111. https://doi.org/10.1016/j.evolhumbehav.2006.09.001

Ichraf, A., Ali, B. M., Khaled, T., Liwa, M., \& Ali, E. (2013). Effect of gender and type of sport on anxiety and self-esteem. International Journal of Humanities and Social Science Invention, 2(3), 55-61.

Köhler, B. (1984). Physische Attraktivität und Persönlichkeitsmerkmale. in Amelang, M., \& Ahrens, H.-J. (Eds.). Brennpunkte der Persönlichkeitsforschung, 1, Göttingen: Verlag für Psychologie Hofgrefe, 139-153.

Landy, D., \& Sigall, H. (1974). Beauty is talent: task evaluation as a function of the performer's physical attractiveness. Journal of Personality and Social Psychology, 29(3), 299-304. https://doi.org/10.1037/h0036018

Mahoney, M. J., \& Avener, M. (1977). Psychology of the elite athlete: An exploratory study. Cognitive Therapy and Research, 1(2), 135-141. https://doi.org/10.1007/BF01173634

Maner J. K., Kenrick, D. T., Becker, V. D., Delton, A. W., Hofer, B., Wilbur, C. J., \& Neuberg, S. L. (2003). Sexually selective cognition: Beauty captures the mind of the beholder. Journal of Personality and Social Psychology, 85(6), 1107-1120. https://doi.org/10.1037/0022-3514.85.6.1107

Mathes, E. W., \& Kahn, A. (1975). Physical attractiveness, happiness, neuroticism, and self-esteem. Journal of Psychology, 90(1), 27-30. https://doi.org/10.1080/00223980.1975.9923921

Mutz, M., \& Meier, H. E. (2016). Successful, sexy, popular: Athletic performance and physical attractiveness as determinants of public interest in male and female soccer players. International Review of the Sociology of Sport, 51(5), 567-580. https://doi.org/10.1177/1012690214545900

Patzer, G. L. (1985). The physical attractiveness phenomena. New York: Plenum Press. https://doi.org/10.1007/978-1-4757-0202-6

Postma, E. (2014). A relationship between attractiveness and performance in professional cyclists. Biology Letters, 10(2), 384-387. https://doi.org/10.1098/rsbl.2013.0966

Rejeski, W., Darracott, C., \& Hutslar, S. (1979). Pygmalion in youth sport: A field study. Journal of Sport Psychology, l(4), 311-319.

Rosar, U., Hagenah, J., \& Klein, M. (2010). Physische Attraktivität und individuelles Leistungsverhalten oder: Warum und wann unattraktive Männer die besseren Fußballer sind. Soziale Welt, 61(1), 51-68. https://doi.org/10.5771/0038-6073-2010-1-51

Rosar, U., Hagenah, J., \& Klein, M. (2014). Physical attractiveness and monetary success in German Bundesliga. Soccer \& Society.

Rosenthal, R., \& Jacobson, L. (1968). Pygmalion in the classroom. The Urban Review, 3(1), 16-20. https://doi.org/10.1007/BF02322211

Shackelford, T. K., \& Larsen, R. J. (1999). Facial attractiveness and physical health. Evolution and Human Behavior, 20(1), 71-76. https://doi.org/10.1016/S1090-5138(98)00036-1

Shoup, M. L., \& Gallup, G. G. (2008). Men's faces Convey Information about Their Bodies and Their Behavior: What You See is What You Get. Evolutionary Psychology, 6(3), 469-479. https://doi.org/10.1177/147470490800600311

Taylor, J. (1987). Predicting athletic performance with self-confidence and somatic and cognitive anxiety as a function of motor and physiological requirements in six sports. Journal of Personality, 55(1), 139-153. https://doi.org/10.1111/j.1467-6494.1987.tb00432.x

Thornton, B., \& Ryckman, R. M. (1991). Relationship between physical attractiveness, physical effectiveness, and self-esteem: a cross-sectional analysis among adolescents, Journal of Adolescence, 14(1), 85-98. https://doi.org/10.1016/0140-1971(91)90047-U 
Williams, K. M., Park, J. H., \& Wieling, M. B. (2010). The face reveals athletic flair: better National Football League quarterbacks are better looking. Personality and Individual Differences, 48(2), 112-116. https://doi.org/10.1016/j.paid.2009.09.003

Woodman, T., \& Hardy, L. (2003). The relative impact of cognitive anxiety and self-confidence upon sport performance: A meta-analysis. Journal of Sports Sciences, 21(6), 443-457. https://doi.org/10.1080/0264041031000101809

World Health Organization. (2015). BMI classification. Retrieved 30 ${ }^{\text {th }}$ September 2015 from http://apps.who.int/bmi/index.jsp?introPage=intro_3.html

Yu, C. C. (2005). Athlete endorsement in the international sports industry: A case study of David Beckham. International Journal of Sports Marketing \& Sponsorship, 6(3), 189-199. https://doi.org/10.1108/IJSMS-06-03-2005-B007

\section{Copyrights}

Copyright for this article is retained by the author(s), with first publication rights granted to the journal.

This is an open-access article distributed under the terms and conditions of the Creative Commons Attribution license which permits unrestricted use, distribution, and reproduction in any medium, provided the original work is properly cited. 